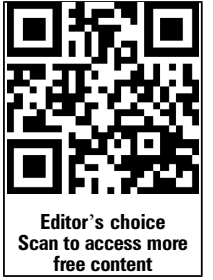

- Additional material is published online only. To view please visit the journal online (http://dx.doi.org/10.1136/ postgradmedj-2014-133094).

${ }^{1}$ Walsall Manor Hospital, Birmingham, UK

${ }^{2}$ Department of Ophthalmology, University Hospitals Birmingham NHS Foundation Trust, Birmingham, UK

${ }^{3}$ NIHR Biomedical Research Centre, Moorfields Eye Hospita NHS Foundation Trust and UCL Institute of Ophthalmology, London, UK

${ }^{4}$ Centre for Health and Social Care Improvement, Faculty of Education Health and Wellbeing, University of Wolverhampton,

Wolverhampton, UK ${ }^{5}$ Eye Department, Kilimanjaro Christian Medical Centre, Moshi, Tanzania

${ }^{6}$ International Centre for Eye Health, Faculty of Infectious and Tropical Diseases, London School of Hygiene and Tropical Medicine, London, UK

\section{Correspondence to} Dr Jeremy Andrew GilmourWhite, Walsall Manor Hospital, Moat Road, Walsall, West Midlands WS29PS, UK; j.gilmour-white@nhs.net

Received 29 October 2014 Revised 9 May 2015 Accepted 25 May 2015 Published Online First 11 June 2015

\title{
Glaucoma awareness and access to healthcare: perceptions among glaucoma patients in Tanzania
}

\author{
Jeremy A Gilmour-White, ${ }^{1}$ Peter Shah, ${ }^{2,3,4}$ Vinette Cross, ${ }^{3,4}$ William Makupa, \\ Heiko Philippin ${ }^{5,6}$
}

\section{ABSTRACT \\ Objective To investigate the barriers to access to eye health services for patients with glaucoma in Tanzania with the aim of identifying key areas for improvement and further research. \\ Design Qualitative investigation using face-to-face semi-structured interviews with patients recruited from the Kilimanjaro Christian Medical Centre (KCMC) outpatient eye clinic. This project is part of the international strategy of the Research into Glaucoma and Ethnicity (ReGAE) programme.}

Methods Interviews were conducted with the help of a translator; all data were transcribed in Swahili and then translated into English. Manual coding and qualitative analysis was used to identify major themes and relevant concepts. Data were collected during May and June 2013.

Main outcome measures Qualitative data on glaucoma awareness and access to healthcare.

Results 12 patients (7 men, 5 women) of mean age 67.5 years (range $53-86$ years) were interviewed. All participants had a previous diagnosis of glaucoma and no other eye conditions. The understanding of glaucoma was limited and the capacity for healthcare providers to improve glaucoma knowledge seemed underused.

Participants had particular difficulty in understanding the aetiology and chronicity of the disease. Socioeconomic factors also posed significant barriers to service usage. Conclusions Among many barriers to access to health services for patients with glaucoma, knowledge of the condition was identified as a key issue. Enhancing the understanding of glaucoma may improve access by triggering earlier presentation, informing those at risk and improving adherence to treatment. This is an area for further research with potential for improving service provision.

\section{INTRODUCTION}

Primary open angle glaucoma (POAG) is the second leading cause of blindness worldwide. The extent of glaucoma is significantly higher among certain ethnic groups, ${ }^{1}$ with the prevalence of POAG highest in Africa. ${ }^{2}$ Studies looking specifically at certain sub-Saharan populations support the view that POAG is a major cause of blindness and that Africans are at increased risk. ${ }^{4-7}$

Chronic disease in low to middle income settings is known to be challenging. ${ }^{8}$ As POAG remains asymptomatic and therefore undetected in most patients until an advanced stage, early intervention is difficult. This means the disease burden remains high despite the existence of several effective treatments. ${ }^{9} 10$ The International Agency for the Prevention of Blindness has labelled glaucoma as a priority issue, with the World Health Organization's Vision 2020 report from 2010 specifying glaucoma as a complex problem where research is required in multiple areas. ${ }^{11}{ }^{12}$ For the purposes of this paper, the term 'glaucoma' is taken to mean POAG.

Tanzania is a low-income country in sub-Saharan Africa with a population of 49.25 million (2013), GDP of US $\$ 43.65$ billion (2013) and life expectancy of 61 years (2012). ${ }^{13}$ Audits of hospitals within Tanzania have shown that approximately $30-50 \%$ of patients with glaucoma are blind when they present to hospital. ${ }^{14}$ Qualitative studies focusing on patients with cataracts have found various barriers to access to eye services including health attitudes, finance, travel, gender differences, family structure and knowledge of the disease. ${ }^{15} 16$ However, the chronic nature of POAG, the delayed onset of symptoms and the prospect of no cure pose different challenges from those of cataracts. Knowledge of the care-seeking behaviour of patients with glaucoma is limited, with few studies carried out within the African hospital setting. ${ }^{17} 18$ It is important to understand why glaucoma patients in Tanzania present late and with advanced disease.

Given the complex issues surrounding effective POAG service provision and the continued worldwide burden of disease despite adequate treatments, the objectives of this qualitative study in Tanzania were threefold: (1) to explore the barriers to access to eye health services for glaucoma patients in Tanzania; (2) to consider the implications for improving service usage both within Tanzania and in the broader context; and (3) to identify key areas to facilitate further culturally sensitive POAG research.

This study forms part of the Research into Glaucoma and Ethnicity (ReGAE) programme, a multiphase multidisciplinary project which aims to reduce avoidable glaucoma blindness. ${ }^{19}$

\section{METHODS \\ Participant selection}

This study was conducted during May and June 2013 at Kilimanjaro Christian Medical Centre (KCMC) in Moshi, Tanzania. KCMC has a large long-standing eye department providing extensive medical and surgical facilities, seeing more than 24000 outpatients per year. Patients were recruited from the outpatient eye clinic on the basis of availability and willingness to share relevant experiences. Patients interviewed had to be aged $>18$ years, to have a previous diagnosis of POAG and no other major eye conditions. Written consent 
was obtained from each participant before interviewing commenced; one patient was illiterate and gave verbal consent.

\section{Questionnaire development}

A semi-structured questionnaire was developed (see online supplementary appendix 1) using a priori assumptions from the literature and personal insight. Questions focused on the key areas of knowledge, access and patient experience, but were kept loose enough to accommodate elaboration by participants. Apparent assumptions were not allowed to impede subject viewpoints; the aim was to create an augmented dataset representing the views of all participants.

\section{Data collection}

Twelve patients were interviewed for $60 \mathrm{~min}$, all digitally recorded with permission. Interviews were conducted in Swahili. Throughout the interviews the Swahili term directly translated as 'pressure of the water of the eyes' was used instead of 'glaucoma', which is only used by the medical profession. In the context of barriers to services, the interviews focused on knowledge of glaucoma, access route and patient experiences. The purpose was to explore attitudes and understanding rather than to educate, but participants could ask questions at the end.

All interviews were transcribed in Swahili and then translated into English so that minimal information was lost or simplified in translation. The following speech data conventions were used to aid conversion of the data into written format for the purposes of analysis (interviewer questions or prompts are displayed in italics): [] clarifications; --. interrupted sentence; (...) word inaudible; (....) several words inaudible; ... short pause.

\section{Data analysis}

Transcriptions were analysed using the process of thematic analysis whereby coded sections of the data were clustered into categories and ultimately themes or concepts. ${ }^{20}$ Interpretations from the data were then validated through an iterative three-stage process. Initial concepts were discussed within the research team, then presented to an expert panel for further elaboration and finally confirmed by review by a senior clinician within Tanzania. The themes were then re-categorised within the overarching headings of knowledge, access and patient experience. Each extract was coded by patient number, gender and age-for example (4: M53).

\section{RESULTS}

\section{Participant characteristics}

Twelve patients ( 7 men, 5 women) of mean age 67.5 years (range 53-86 years) were interviewed. All participants were born in Tanzania. The majority belonged to the local 'Chagga' tribe and four individuals belonged to others: 'Maasai', 'Pare', 'Sambaa' and 'Mngoni'. Most participants had an educational level of 4-7 years of primary school with only one completing secondary education. The distance travelled to reach KCMC varied considerably, ranging from $5 \mathrm{~km}$ for those living within Moshi to $678 \mathrm{~km}$ for one patient from the distant town of 'Shinyanga'; the mean distance travelled was $151.5 \mathrm{~km}$. Relevant clinical information relating to disease progression for each participant is shown in table 1. Patients with diabetes or hypertension who were included had no eye disease related to these conditions.

\section{Emerging themes}

Many different themes emerged from the interview data. Those most relevant to the research objectives within the interview framework of knowledge, access and patient experiences supported by participant extracts are shown in table 2 .

\section{Knowledge of glaucoma}

Participant knowledge of glaucoma was broadly limited across all areas, the exception being that the majority $(n=10)$ knew

Table 1 Relevant clinical information relating to disease progression for each participant

\begin{tabular}{|c|c|c|c|c|c|c|c|}
\hline Patient no & $\begin{array}{l}\text { Years with } \\
\text { POAG diagnosis }\end{array}$ & Comorbid state & $\begin{array}{l}\text { CDR } \\
\text { RE/LE }\end{array}$ & $\begin{array}{l}\text { VF }(\mathrm{MD}(\mathrm{dB})) \\
\text { RE } \\
\text { LE }\end{array}$ & $\begin{array}{l}\text { VA } \\
\text { RE } \\
\text { LE }\end{array}$ & Surgical history & Current treatment \\
\hline 1 & 2.8 & $\mathrm{~N} / \mathrm{A}$ & $1.0 / 1.0$ & $\begin{array}{l}-4 \\
-7\end{array}$ & $\begin{array}{l}6 / 18 \\
6 / 18\end{array}$ & $\mathrm{~N} / \mathrm{A}$ & BE Tim \\
\hline 2 & 0.0 & $\mathrm{~N} / \mathrm{A}$ & $1.0 / 1.0$ & $\mathrm{~N} / \mathrm{A}$ & $\begin{array}{l}\mathrm{PL} \\
\mathrm{PL}\end{array}$ & N/A & BE Tim \\
\hline 3 & 4.6 & $\mathrm{~N} / \mathrm{A}$ & $1.0 / 1.0$ & $\mathrm{~N} / \mathrm{A}$ & $\begin{array}{l}\text { CF } \\
P L\end{array}$ & $\mathrm{~N} / \mathrm{A}$ & BE Tim \\
\hline 4 & 4.4 & $\mathrm{~N} / \mathrm{A}$ & $1.0 / 1.0$ & $\mathrm{~N} / \mathrm{A}$ & $\begin{array}{l}\mathrm{HM} \\
\mathrm{PL}\end{array}$ & RE TRB & BE Tim \\
\hline 5 & 1.1 & DM2, HTN & $0.9 / 0.9$ & $\begin{array}{l}-30 \\
-10\end{array}$ & $\begin{array}{l}6 / 18 \\
6 / 18\end{array}$ & LE TRB & $\mathrm{N} / \mathrm{A}$ \\
\hline 6 & 2.5 & HTN & $0.6 / 0.8$ & $\begin{array}{l}-9 \\
-7\end{array}$ & $\begin{array}{l}6 / 12 \\
6 / 9\end{array}$ & N/A & BE Tim \\
\hline 7 & 0.0 & HTN & $1.0 / 0.3$ & $\begin{array}{l}-25 \\
-3\end{array}$ & $\begin{array}{l}6 / 12 \\
6 / 6\end{array}$ & RE TRB & N/A \\
\hline 8 & 0.2 & DM2, HTN & $0.8 / 0.9$ & $\begin{array}{l}-8 \\
-22\end{array}$ & $\begin{array}{l}6 / 18 \\
C F\end{array}$ & RE TRB & LE Tim \\
\hline 9 & 3.4 & Keloids & $1.0 / 1.0$ & $\begin{array}{l}-33 \\
-32\end{array}$ & $\begin{array}{l}\mathrm{HM} \\
6 / 60\end{array}$ & LE TRB & BE Tim \\
\hline 10 & 0.0 & N/A & $0.9 / 0.9$ & $\begin{array}{l}-25 \\
-23\end{array}$ & $\begin{array}{l}6 / 24 \\
6 / 12\end{array}$ & N/A & BE Tim, Lat \\
\hline 11 & 0.4 & $\mathrm{~N} / \mathrm{A}$ & $0.4 / 1.0$ & $\begin{array}{l}-6 \\
-33\end{array}$ & $\begin{array}{l}6 / 9 \\
6 / 24\end{array}$ & N/A & BE Tim \\
\hline 12 & 0.8 & DM2, HTN & $0.9 / 0.6$ & $\begin{array}{l}-30 \\
-28\end{array}$ & $\begin{array}{l}6 / 60 \\
6 / 12\end{array}$ & N/A & BE Tim, Lat \\
\hline
\end{tabular}

CDR, cup disk ratio; DM2, diabetes mellitus type 2; HTN, hypertension; POAG, primary open angle glaucoma; RE/LE, right/left eye. 
Table 2 Themes most relevant to the research objectives emerging from the interview framework of knowledge, access and patient experiences supported by participant extracts

\begin{tabular}{|c|c|c|c|c|c|}
\hline \multirow{2}{*}{$\begin{array}{l}\text { Interview } \\
\text { focus }\end{array}$} & \multirow{2}{*}{$\begin{array}{l}\text { Emerging themes } \\
\text { Confusion about cause }\end{array}$} & \multicolumn{4}{|l|}{ Interview extracts } \\
\hline & & $\begin{array}{l}\text { Because we are in villages far from specialists so } \\
\text { we can't know. What causes? (3: M64) }\end{array}$ & $\begin{array}{l}\text { I gave birth too much that's why I keep on falling sick; } \\
\text { that's why I have pressure of the eye. (6: F74) }\end{array}$ & $\begin{array}{l}\text { Everyone knows its causes; too } \\
\text { much thinking...(9: M77) }\end{array}$ & $\begin{array}{l}\text { What do you think causes the eye pressure? } \\
\text { Diabetes. (12: F73) }\end{array}$ \\
\hline & $\begin{array}{l}\text { Unaware of risk } \\
\text { factors }\end{array}$ & $\begin{array}{l}\text { I don't know about eyes because I have blood } \\
\text { pressure I don't [know] whether it is the one } \\
\text { causing problems. Are they related? (1: M79) }\end{array}$ & $\begin{array}{l}\text { Mama do you think glaucoma is a family problem? } \\
\text { Ahah [refuses] in my family I am the only one with eye } \\
\text { problems. (6: F74) }\end{array}$ & $\begin{array}{l}\text { I want to know why these } \\
\text { diseases disturb aged people } \\
\text { only (Pause) and not youth... } \\
\text { (1: M79) }\end{array}$ & $\begin{array}{l}\text { There is no blindness in our family, except that } \\
\text { now I know about this problem I will tell my } \\
\text { children to come for medical examination. } \\
\text { (5: M60) }\end{array}$ \\
\hline & $\begin{array}{l}\text { Limited understanding } \\
\text { of symptoms }\end{array}$ & $\begin{array}{l}\text { Personally my eyes used to itch and I could not } \\
\text { see properly sometimes I weep, and my eyes } \\
\text { itches... (3: M64) }\end{array}$ & $\begin{array}{l}\text { I may be walking and suddenly I see like there is } \\
\text { smoke all over, even now if I remove glasses I see } \\
\text { smoke. (5: M60) }\end{array}$ & $\begin{array}{l}\text { Yeah sometimes when you focus } \\
\text { straight you something like a } \\
\text { cloud. (4: M53) }\end{array}$ & $\begin{array}{l}\text { I didn't understand because I was not told } \\
\text { anything. } \\
\text { (7: M86) }\end{array}$ \\
\hline & Glaucoma curable & $\begin{array}{l}\text { It will be helpful if you will be able to tell me } \\
\text { what to eat? So that my eyes can be healed. } \\
(2: \text { F58) }\end{array}$ & Will I keep on coming for the rest of my life? (6: F74) & $\begin{array}{l}\text { My opinion is I beg you to help } \\
\text { me; for these---. so that I can be } \\
\text { able to see. } \\
\text { (8: M56) }\end{array}$ & $\begin{array}{l}\text { How long do you think the treatment will take? } \\
\text { Honestly I don't know. } \\
(10: \text { F76) }\end{array}$ \\
\hline & Eye not general health & $\begin{array}{l}\text { If you eat good meal--. if you eat everything } \\
\text { comes around you will you have good health--. } \\
\text { we get poor health because sometimes we lack } \\
\text { [food]. (6: F74) }\end{array}$ & $\begin{array}{l}\text { I am healthy because I don't have any other problem } \\
\text { apart from eyes. (7: M86) }\end{array}$ & By working and food. (1: M79) & $\begin{array}{l}\text { Health is all about body cleanliness, food with } \\
\text { all nutrients. (2: F58) }\end{array}$ \\
\hline \multirow[t]{3}{*}{ Access } & Trigger is loss of vision & $\begin{array}{l}\text { My eyes started to see blue. I asked mama why } \\
\text { are my eyes doing this? She told me to go to } \\
\text { Mawenzi [hospitall]. (7: M86) }\end{array}$ & $\begin{array}{l}\text { I could see as usual but it lose light; when the } \\
\text { situation turn worse I went Mawenzi hospital. (8: M56) }\end{array}$ & $\begin{array}{l}\text { It is because I could not see } \\
\text { properly. } \\
\text { (6: F74) }\end{array}$ & $\begin{array}{l}\text { Loss of eye long sight, and ability to see } \\
\text { properly. } \\
\text { (5: M60) }\end{array}$ \\
\hline & Cost is an issue & $\begin{array}{l}\text { For rural people medical cost are too high even } \\
\text { though it is not much but we find it high because } \\
\text { we can even spend a year without getting } \\
\text { anything mhh. (3: M64) }\end{array}$ & $\begin{array}{l}\text { Funds actually are sometimes and if you see also in the } \\
\text { file you can see there is a time I--. I used to stay for } \\
\text { maybe } 1 \text { year or more than--- Than--. Than yeah } \\
\text { without coming... (4: M53) }\end{array}$ & $\begin{array}{l}\text { She used to come here; but now } \\
\text { days she cannot afford due to } \\
\text { distance and costs. (8: M56) }\end{array}$ & $\begin{array}{l}\text { One cannot see at all I asked her to come with } \\
\text { me she said she doesn't have money; I asked her } \\
\text { why does she have children if they can't help } \\
\text { her? (6: F74) }\end{array}$ \\
\hline & Hospital first & I always come to hospital (1: M79) & $\begin{array}{l}\text { From the beginning I went to Mawenzi (hospital). } \\
\text { (7: M86) }\end{array}$ & $\begin{array}{l}\text { In the beginning I went to } \\
\text { Hospital--.. a dispensary (8: M56) }\end{array}$ & $\begin{array}{l}\text { lelp--. it was a problem--. it is only here in } \\
\text { KCMC. } \\
(9: \text { M77) }\end{array}$ \\
\hline \multirow[t]{2}{*}{ Experience } & KCMC referral centre & $\begin{array}{l}\text { I was referred from Selian Hospital after realizing } \\
\text { that they have failed (Pause) they said specialists } \\
\text { are in KCMC... (2: F58) }\end{array}$ & $\begin{array}{l}\text { I went to a certain hospital there and I was referred to } \\
\text { Same from there I was referred to KCMC. (6: F74) }\end{array}$ & $\begin{array}{l}\text { I used to go to Kibosho they } \\
\text { referred me here. (10: F76) }\end{array}$ & $\begin{array}{l}\text { I used to go to Mawenzi and they transferred me } \\
\text { to here. (12: F73) }\end{array}$ \\
\hline & Not told diagnosis & $\begin{array}{l}\text { Did you know glaucoma before this day? } \\
\text { No. (2: F58) }\end{array}$ & $\begin{array}{l}\text { Did you know glaucoma before today? } \\
\text { I didn't know about it. (3: M64) }\end{array}$ & $\begin{array}{l}\text { None of them told me about it; } \\
\text { it is the last doctor who told } \\
\text { me. (7: M86) }\end{array}$ & $\begin{array}{l}\text { Did you know about eyes pressure of glaucoma } \\
\text { before today? } \\
\text { I didn't know-.- They also didn't know. (12. F73) }\end{array}$ \\
\hline
\end{tabular}

KCMC, Kilimanjaro Christian Medical Centre. 
that without treatment there was a risk of progression to blindness-for example, 'I think if I don't use medicine I will become blind' (6: F74).

\section{Confusion about cause}

Understanding the cause of glaucoma was the area of greatest confusion. None of the participants comprehended the multifactorial aetiology. Four participants said they did not know the cause. The majority had their own ideas including hypertension, diabetes, trauma, multiparity and over-thinking. The most repeated theme among these was diabetes, which was suggested by several participants $(n=3)$.

Oh that can cause. I don't know what does cause that? (4: M53).

But I was told most times diabetic people get this problem. (11: F54)

\section{Unaware of risk factors}

The risk factor of family history was a specific focus within the interviews and participants had a poor appreciation of the hereditary nature of POAG and inherent increased risk for their families. The majority were insistent that they were the only ones with glaucoma within their families, and even those who knew of the risk were unsure what action they should take. Post interview participants were grateful for being informed of these matters and stated their intention to go home and encourage their family members to get examined.

There is no blindness in our family, except that now I know about this problem I will tell my children to come for medical examination. (5: M60).

It is not inherited, it is a disease like others. (8: M56)

Only a few participants were aware that increasing age was also a risk factor and, in these cases, there was again confusion. Hypertension and diabetes were also thought to be causes, but mostly by diabetics.

In 2002 I became diabetic, since then the eye problem started; in August 2008 I realised the eye problem; so I think the two problems blood pressure and diabetes caused the problems to my eyes. (10: F76).

\section{Limited understanding of symptoms}

Knowledge of the symptoms, diagnosis and treatments was particularly limited to their own individual experiences. POAG causes gradual painless vision loss yet there was considerable variety in the descriptions of the symptoms including 'body become weak', 'see darkness ahead', 'swelled and had water', 'eyes itch', 'eyes become hot', 'eyes were boiling' and 'eye ache'. Although the majority of patients $(n=10)$ described a certain degree of vision loss, only a few $(n=4)$ depicted the typical presentation of painless loss. Even in these cases it was clear the information came from their experiences rather than any prior knowledge of POAG. May be the one I experienced failure to see clearly; I think that is
amongst

Failure to see. Which other one?

That is the only one I know. (11: F54)

They claim pain; but mine had no pain before I have on the operation on my eyes--. it started later (....) (10: F76)

\section{Glaucoma is curable}

There was a lack of appreciation of the chronicity of the disease. This was evident indirectly when participants asked how long they would be on their medication, and directly when enquiring as to how they might be cured.

Honestly I cannot know it will take how long (pause) I come for treatment--. treatment is what can cause you to heal may be? You may think you will get healed. (9: M77)

Ohh ok maybe to ask whether is it--. It was a time that problem can be off--. It can still

You mean if there's a time that glaucoma be removed...

Yeah. (4: M53)

\section{Eye is not an aspect of general health}

Although most participants had a positive attitude to maintaining general health, this was mostly limited to eating 'good food' or 'balanced diet' and eye care was never a feature in any health promotional behaviours. One participant even reflected on his delay in presentation and expressed a desire to help others by encouraging them to present earlier.

I will help others with the words you gave me--. but they should see a doctor immediately not delay like me because I was not aware--. if I was aware I could have come early--. I struggled at the beginning. (8: M56)

\section{Access to services}

Access is a broad term used to describe the patient pathway and can be divided into two key areas: initial trigger to attend and travel to and from hospital.

\section{Main trigger to attend is loss of vision}

In all participants except one, the initial trigger to attend hospital was an increasing symptom set and this always included a degree of visual loss. Often vision was specified as the key trigger-for example, 'It is because I could not see properly' (6: F54). Several participants described a delay in presentation evidenced by their relatives noticing the symptoms.

We talk about how eye disease disturbs and they tell me; father go to the hospital please. (1: M79)

Yes yes I--. because when I--. Sometimes when I drive I go outside the road. I sometimes I...I go off to the road and sometimes my wife asked why are you going to off the road. (4: M53)

\section{Travel to and from hospital: cost is an issue}

Travelling to and from hospital was a major problem, the primary issue being financial. Although often travelling long distances, participants rarely complained about the associated physical difficulties but consistently identified costs as the barrier. For the majority without medical insurance, the cost of medicines and procedures posed a similar difficulty. Many also described people from their communities who could not afford to attend clinic at all.

One cannot see at all I asked her to come with me, she said she doesn't have money. (6: F74)

I think medical costs because we are not financial stable and we depend much on cultivation and now days we get nothing. (3: M64)

It is because I pay transport and when I reach here I need to pay for a place to sleep. (11: F54)

\section{Hospital first point of access}

Nearly all participants described hospitals as being their first point of access and denied any other sources of care. 
I got this eye problem recently it started the beginning of last year; I went to dispensaries and last year November I went to Mawenzi Hospital. (3: M64)

Uh! I don't go any other place. (1: M79)

\section{Patient experiences}

Participants were very positive about the services provided by KCMC, describing them as 'good', 'no discrimination' and 'specialists'.

\section{KCMC referral centre}

Most participants $(n=9)$ had been referred to KCMC from surrounding hospitals and the view that KCMC was a specialist referral centre was a consistent theme. The only criticisms of the department focused on waiting times. This was a particular difficulty for those travelling long distances. One woman suggested that KCMC should prioritise seeing long distance patients first.

I think they should consider farthest people--. like me I arrived; but I have no one to host me so I had to go to a guest house; it cost more. (11: F54).

\section{Unaware of diagnosis}

Many of the participants $(n=5)$ said the interview was the first time they had heard of glaucoma and, of the remainder, only a few $(n=2)$ knew about glaucoma before they came to KCMC. Whether this was due to not being clearly informed or inability to remember cannot be known for certain. However, the testimonies do suggest that patients are poorly informed of their diagnosis and associated risk factors.

What eye problem do you think you have up to now?

Honestly I don't know; after they told me I have...? Honestly I don't know

You don't know? Were you not told?

No. (10: F76)

I was not told but the apart from the drops they gave me; they didn't say any other thing. (12: F73)

Swahili language as an additional barrier:

Participants used the terms 'pressure of the eye' (presha ya macho) and 'water of eyes' (maji ya jicho) to describe glaucoma, but the most accurate name in Swahili is 'pressure of the water of the eye' (shinikizo la maji ya jicho). Most of the time these names were used interchangeably and often caused confusion. Notably, the English term 'glaucoma' is used almost exclusively by the medical profession.

Like now I was told I am sick and it might be pressure of eye [presha ya macho] or water of eyes [maji ya jicho]--. how will this water finish, how will you help me? (3: M64)

Don't you think pressure of the eye [shinikizo ya macho] is a latest disease? I was so surprised when I was told it was pressure of the eye [presha ya macho], we were amazed. (9: M77)

\section{DISCUSSION}

The interviews clearly showed that participants lacked understanding of glaucoma. Even after presentation, participants remained poorly informed and many were not aware of their diagnosis. Confusions over the cause, risk factors and chronicity of the disease were common and a potential source of poor adherence to treatment. The consistent trigger for presentation to hospital was symptomatic loss of vision. There was no appreciation of early diagnosis improving outcome and the potential for screening family members was underused. There were also significant financial barriers to access, both in terms of travel and medical expenses.

Glaucoma is a difficult concept for patients to grasp because of its long asymptomatic stage and chronic nature. Disease without immediate symptoms is not reflected in the Swahili language where the word for sickness (ugonjwa) implies pain or ailment associated with the condition. Additional confusion is caused by the variety of names for glaucoma within the Swahili language. This presents considerable innate and linguistic challenges to glaucoma health education.

Emphasis on treatment being preventive rather than curative would foster greater understanding of the importance of continuing treatment. Giving patients insight into the cause of POAG may reduce patient distress and reduce ineffective health behaviours. The KCMC Eye Department provides a trained nurse for counselling patients with newly diagnosed glaucoma, which should contribute to an increased awareness of glaucoma. This system provides a potential area for further research and could be an effective tool to improve patient knowledge of glaucoma.

Financial constraints will always limit the ability to attend hospital and pay for medications or procedures. Medical insurance was a great help to many and this is a resource that should be maximally used. Informing patients about health insurance may encourage wise financial behaviours and insurance usage. Installing a protocol to see long distance patients early in the day might allow people who cannot afford accommodation to attend hospital.

It is notable that qualitative research of barriers to access for glaucoma service users in the UK has raised similar issues, ${ }^{21}$ although less prominent and extensive. This study supports the limited existing body of evidence that identifies patient understanding of glaucoma as a significant barrier to accessing eye services in Africa. ${ }^{18} 22-24$

Twelve $60 \mathrm{~min}$ interviews were considered sufficient to explore this specific context in depth. However, given the local qualitative nature of the investigation, caution should be exercised in drawing definitive general conclusions. With little glaucoma detected in the African context and even less undergoing active treatment, significant bias is introduced from a sample recruited from the hospital setting. This makes the major findings about the lack of understanding of the condition all the more surprising and concerning.

This study has identified several key areas for consideration in relation to improving glaucoma service provision. Further qualitative research exploring the perspectives of non-hospital attenders would provide a useful comparison. Glaucoma education is an important area for intervention and this provides a focus for

\section{Main messages}

- Participant understanding of glaucoma was significantly limited in this study of 12 patients recruited from the Kilimanjaro Christian Medical Centre (KCMC) outpatient eye clinic in Tanzania.

- Glaucoma poses a unique set challenges to patient education in Tanzania

- Symptomatic loss of vision was the main trigger for hospital attendance at KCMC 


\section{Current research questions}

- Why are glaucoma patients in Tanzania so uninformed about their condition?

- How can glaucoma health education be improved within the hospital setting?

- Does improving patient knowledge of glaucoma increase service uptake?

- What are the barriers to access to glaucoma services for non-hospital attenders?

subsequent research. The role of post-diagnosis counselling and appropriate topics to cover could be explored.

Acknowledgements We would like to thank all those who collaborated to facilitate the success of this research, particularly participating patients and staff from the Ophthalmology Department of KCMC.

Contributors All authors contributed to the research design and construction of the manuscript.

Competing interests None declared.

Ethics approval Ethical approval was obtained from the research and ethics committee of Kilimanjaro Christian Medical University College in Moshi, Tanzania.

Provenance and peer review Not commissioned; externally peer reviewed.

Data sharing statement Full transcripts of all interviews in both Swahili and English are available from the corresponding author.

\section{REFERENCES}

1 Quigley HA, Broman AT. The number of people with glaucoma worldwide in 2010 and 2020. Br J Ophthalmol 2006:903:262-7.

2 Thylefors B, Négrel AD. The global impact of glaucoma. Bull World Health Organ 1994;72:323-6.

3 Tham Y, Li X, Wong TY, et al. Global prevalence of glaucoma and projections of glaucoma burden through 2040: a systematic review and meta-analysis. Ophthalmology 2014;121:2081-90.

4 Poole TRG. Causes of blindness in Northern Tanzania: a hospital and rural health centre based study. Int Ophthalmol 2001;24:195-8.

5 Ntim-Amponsah CT, Amoaku WM, Ofosu-Amaah S, et al. Prevalence of glaucoma in an African population. Eye 2004;18:491-7.

6 Buhrmann RR, Quigley HA, Barron Y, et al. Prevalence of glaucoma in a rural east African population. Invest Ophthalmol Vis Sci 2000;41:40-8.
7 Lewallen S, Courtright P. Blindness in Africa: present situation and future needs. $\mathrm{Br} J$ Ophthalmol 2001:85:897-903.

8 Goudge J, Gilson L, Russel S, et al. Affordability, availability and acceptability barriers to health care for the chronically ill: Iongitudinal case studies from South Africa. Health Serv Res 2009;9:75

9 Gessesse GW, Damii KF. Advanced glaucoma: management pearls. Middle East Afr J Ophthalmol 2013;20:975-1599.

10 Quigley HA, Buhrmann RR, West SK, et al. Long term results of glaucoma surgery among participants in an East African population survey. Br J Ophthalmol 2000;84:860-4.

11 Kyari F, Abdull MM, Bastawrous A, et al. Epidemiology of glaucoma in sub-Saharan Africa: prevalence, incidence and risk factors. Middle East Afr J Ophthalmol 2013:20:111-25.

12 International Agency for the Prevention of Blindness. IABP Vision 2020 Report. UK: Trolley Ltd, 2010. http://www.iapb.org/sites/iapb.org/files/State\%20of\%20the\% 20World\%20Sight_2010.pdf (accessed 20 Feb 2015).

13 The World Bank. 2012 data, Tanzania. http://www.data.worldbank.org/country/ tanzania (accessed 4 Jun 2015)

14 Mafwiri M, Bowman $\mathrm{R}$, Wood $\mathrm{M}$, et al. Primary open-angle glaucoma presentation at a tertiary unit in Africa: intraocular pressure levels and visual status. Ophthalmic Epidemiol 2005;12:299-302.

15 Geneau R, Lewallen S, Bronsard A, et al. The social and family dynamics behind the uptake of cataract surgery: findings from Kilimanjaro region, Tanzania. $\mathrm{Br} J$ Ophthalmol 2005;89:1399-402.

16 Bronsard A, Shirima S. Cataract surgery: ensuring equal access for boys and girls. Community Eye Health 2009:22:28-9.

17 Jackson DJ, Razai MS, Falama R, et al. The clinical characteristics of patients with glaucoma presenting to Botswana healthcare facilities: an observational study. BMJ Open 2014;4:1-7

18 Lewallen $\mathrm{S}$, Hassan $\mathrm{HG}$, Al Attas $\mathrm{AH}$, et al. A population-based study of care-seeking behaviour in rural Tanzanians with glaucoma blindness. J Glaucoma 2011;20:361-5

19 Shah P, Cross V. ReGAE 1: Using the Shah-Cross model as an orientating framework in African Caribbean research. Eye 2006;20:988-97.

20 Braun V, Clarke V. Using thematic analysis in psychology. Qual Res Psychol 2006;3:77-101.

21 Cross V, Shah P, Bativala R, et al. ReGAE 2: Glaucoma awareness and the primary eye-care service: some perceptions among African Caribbeans in Birmingham UK. Eye 2007;21:912-20.

22 Geneau R, Massae $\mathrm{P}$, Courtright $\mathrm{P}$, et al. Using qualitative methods to understand the determinants of patients' willingness to pay for cataract surgery: a study in Tanzania. Soc Sci Med 2008;66:558-68.

23 Tenkir A, Solomon B, Deribew A. Glaucoma awareness among people attending ophthalmic outreach services in Southwestern Ethiopia. BMC Ophthalmol 2010;10:1471-2415.

24 Syed A, Polack S, Eusebio C, et al. Predictors of attendance and barriers to cataract surgery in Kenya, Bangladesh and the Philippines. Disabil Rehabil 2013; 35:1660-7. 